\title{
Unbalanced Voltages Impacts on the Energy Performance of Induction Motors
}

\author{
Enrique C. Quispe ${ }^{1}$, Iván D. López ${ }^{2}$, Fernando J. T. E. Ferreira ${ }^{3}$, Vladimir Sousa ${ }^{4}$ \\ ${ }^{1,2}$ Energy and Mechanical Department, Universidad Autónoma de Occidente, Calle 25 No.115-85, Cali, Colombia \\ ${ }^{3}$ Electrical and Computer Engineering Department, University of Coimbra, Rua Guilherme Moreira no 12, Coímbra, \\ Portugal \\ ${ }^{4}$ Energy Department, Universidad de la Costa, Calle 58 No.55-66, Barranquilla, Colombia
}

\begin{tabular}{l}
\hline Article Info \\
\hline Article history: \\
Received Jan 21, 2018 \\
Revised Apr 30, 2018 \\
Accepted May 7, 2018 \\
\hline Keyword: \\
Efficiency \\
Energy performance \\
Induction motors \\
Losses \\
Power factor \\
Voltage unbalance \\
\hline
\end{tabular}

\begin{abstract}
This paper presents the results of a study about the effects of unbalanced voltages on the energy performance of three-phase induction motors. The principal contribution of this paper is that presents a detailed analysis of the influence of positive and negative sequence voltage components and the angle between them on several characteristics such as: line currents, losses, efficiency and power factor under different voltage unbalanced conditions. A three-phase induction motor of 3 HP was used as a case study. The results of the investigation show that the positive sequence voltage must be considered together with the voltage unbalance factor (VUF) or percent voltage unbalance (PVU) index to evaluate the performance of the induction motor. It is also shown that the behavior of the motor load influences on the positive sequence parameters next to the voltage, while in the case of negative sequence only influences the negative sequence voltage.
\end{abstract}

Copyright $\odot 2018$ Institute of Advanced Engineering and Science. All rights reserved.

\section{Corresponding Author:}

Vladimir Sousa Santos

Energy Department, Universidad de la Costa, Calle 58 No.55-66, Barranquilla, Colombia.

email: vsousa1@cuc.edu.co

\section{INTRODUCTION}

The analysis of induction motor operation is important because these represent most of the installed load in industrial systems due to its reliability, power to size ratio, ruggedness and relatively low cost [1]. In addition, they consume approximately $68 \%$ of the electric power in this sector [2]. The problems associated with energy quality, constitute an everyday phenomena. Unbalanced voltages, which in most cases occurs associated with voltage deviations, is one of the most common in terms of energy quality and has a direct influence on the increase of losses in electric motors and systems [3].

The presence of unbalance is due mainly to the existence of unbalanced loads, unsymmetrical transformer windings or transmission impedances, large single-phase loads, incomplete transposition of transmission lines, open delta transformer connections, blown fuses on three-phase capacitor bank, operation of single-phase loads at different times, defective transformers in power systems, or when one of the threephases of the motor is open [4], [5]. These problems significantly affect the efficiency and other operational characteristics of the induction motors.

The operation of induction motor under voltage unbalance conditions produce two rotating fields in the motor air gap, one in the forward direction of the motor rotation (positive sequence) and another in the opposite direction (negative sequence), giving as result an elliptical field [6]. Consequently for a given load and percentage of voltage unbalance, the phase currents and temperature rise much greater than when operating under the same load conditions and balanced voltages, affecting the motor performance. 
The effects of voltage unbalance on the motor such as, unbalanced currents, temperature rise, increased losses, output power and torque reduction, pulsation torques and speed reduction, has been studied by several authors, [7]-[14]. These studies are generally focused on the effects caused by the negative sequence component of voltage. Other authors have considered both the positive and negative sequence voltage [2]-[4], [15]-[17].

This paper presents a new analysis focused in the qualitative and quantitative effects of voltage unbalance on the line currents, losses, efficiency and power factor on induction motors. The analysis is based on the symmetrical components method and considers the specific effects of the positive and negative sequence voltage components and the angle between them. The equations described are a useful tool to quantify the effects of voltage unbalance in induction motors.

\section{RESEARCH METHOD.}

This section explains the model of the equivalent circuit, the derived equations and the diagram of the energy flow corresponding to the operation of induction motors operating with unbalanced voltages. In addition, the equations that allow analyzing the effect of the motor load on current unbalance are described, as well as the effect of unbalanced voltage on motor losses, efficiency and power factor.

\subsection{Equivalent circuit, efficiency equation and flux energy diagram for unbanced voltage}

The operation of induction motors fed with unbalanced voltages can be analysed by applying the theory of rotating fields by the equivalent circuits presented in Figure 1. Figure 1(a) represents the positive sequence component corresponding to the flow that rotates in the direction of the motor shaft rotation. Figure 1(b) represents the negative sequence component corresponding to the flow that opposes to motor shaft rotation. The effect of displacement current due to the frequency of the negative sequence current is represented in Figure 1(b) [18]. The voltages and currents of positive and negative sequence are decomposed from the line values by applying the method of the symmetric components [3].

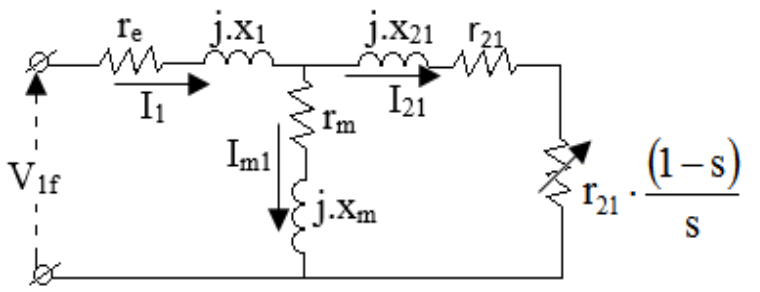

(a)

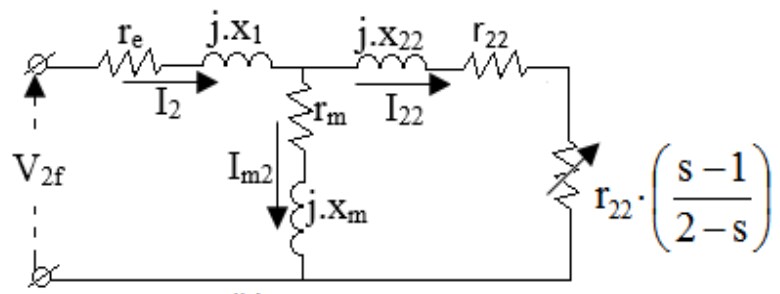

(b)

Figure 1. Equivalente circuits of (a) positive and (b) negative sequence of motors operating with unbalanced voltage

In Figure $1, V_{1 f}$ and $V_{2 f}$ are voltage of positive and negative sequence per phase respectively in $(\mathrm{V})$, $I_{1}$ and $I_{2}$ are input current of positive and negative sequence respectively in (A), $I_{m 1}$ and $I_{m 2}$ are magnetization current of positive and negative sequence respectively in (A), $\mathrm{I}_{21}$ and $\mathrm{I}_{22}$ are rotor current of positive and negative sequence respectively in $(\mathrm{A}), \mathrm{r}_{\mathrm{e}}$ is stator resistance in $(\Omega), \mathrm{x}_{1}$ is stator leakage reactance in $(\Omega), \mathrm{r}_{\mathrm{m}}$ is core loss resistance in $(\Omega), \mathrm{x}_{\mathrm{m}}$ is magnetizing reactance in $(\Omega), \mathrm{x}_{21}$ and $\mathrm{x}_{22}$ are rotor leakage reactance of positive and negative sequence respectively in $(\Omega), \mathrm{r}_{21}$ and $\mathrm{r}_{22}$ are rotor resistance of positive and negative sequence respectively in $(\Omega)$ and $\mathrm{s}$ is slip in (p.u).

According to Figure 1, the electrical power consumed by the motor $\mathrm{P}_{\text {elec }}$ when it is fed with unbalanced voltages, has two components a positive sequence electrical power $\mathrm{P}_{1}$ and a negative sequence electrical power $\mathrm{P}_{2}$.

$$
\begin{aligned}
& \mathrm{P}_{\text {elec }}=\mathrm{P}_{1}+\mathrm{P}_{2} \\
& \mathrm{P}_{\text {elec }}=3 \cdot \mathrm{V}_{1 \mathrm{f}} \cdot \mathrm{I}_{1} \cdot \mathrm{Fp}_{1}+3 \cdot \mathrm{V}_{1 \mathrm{f}} \cdot \mathrm{I}_{1} \cdot \mathrm{Fp}_{2}
\end{aligned}
$$

where $P_{\text {elec, }} P_{1}$ and $P_{2}$ are the total, positive sequence and negative sequence of electrical power consumed by the motor respectively in $(\mathrm{W}), \mathrm{Fp}_{1}$ and $\mathrm{Fp}_{2}$ are the power factor of the positive and negative equivalent circuits respectively in (p.u). 
Analogously, the motor output power or shaft power $\mathrm{P}_{\text {out }}$, can be decomposed as the sum of positive sequence output power $\mathrm{P}_{\text {out1 }}$ and negative sequence output power $\mathrm{P}_{\text {out } 2}$ as describe following.

$$
\begin{aligned}
& \mathrm{P}_{\text {out }}=\mathrm{P}_{\text {out } 1}+\mathrm{P}_{\text {out } 2}-\mathrm{P}_{\mathrm{fw}} \\
& \mathrm{P}_{\text {out }}=3 \cdot \mathrm{r}_{21} \cdot \frac{(1-\mathrm{s})}{\mathrm{s}} \cdot \mathrm{I}_{21}^{2 .}+3 \cdot \mathrm{r}_{22} \cdot\left(\frac{\mathrm{s}-1}{2-\mathrm{s}}\right) \cdot \mathrm{I}_{22}^{2}-\mathrm{P}_{\mathrm{fw}}
\end{aligned}
$$

where $\mathrm{P}_{\text {out, }} \mathrm{P}_{\text {out } 1}$ and $\mathrm{P}_{\text {out } 2}$ are the total, positive sequence and negative sequence of output power respectively in $(\mathrm{W}), \mathrm{P}_{\mathrm{fw}}$ is the friction and windage losses in (W)

In steady state operation, the slip varies between 0.01 and 0.05 , therefore, according to Equation (4), in this zone the mechanical power generated by the negative sequence field $\mathrm{P}_{\text {out } 2}$ is negative. It can be interpreted as the power expended in overcoming the torque produced by the magnetic flux of negative sequence. In Equation (5), it is shown that this power dissipates as copper loss of the negative sequence circuit. This loss has two sources: the electromagnetic power that transfers the negative sequence source to airgap $\mathrm{P}_{\mathrm{ag} 2}$ and mechanical power expended in overcoming the torque produced by the negative sequence magnetic flow $\mathrm{P}_{\mathrm{mec} 2}$.

$$
\begin{aligned}
& \mathrm{P}_{\mathrm{cu} 2}=\mathrm{P}_{\mathrm{ag} 2}-\mathrm{P}_{\mathrm{mec} 2} \\
& \mathrm{P}_{\mathrm{cu} 2}=3 \cdot \frac{\mathrm{r}_{22}}{(2-\mathrm{s})} \cdot \mathrm{I}_{22}^{2}-3 \cdot\left(\frac{\mathrm{s}-1}{2-\mathrm{s}}\right) \cdot \mathrm{r}_{22} \cdot \mathrm{I}_{22}^{2} \\
& \mathrm{P}_{\mathrm{cu} 2}=3 \cdot \mathrm{r}_{22} \cdot \mathrm{I}_{22}^{2}
\end{aligned}
$$

Where $\mathrm{P}_{\text {cu2 }}$ is the copper loss of negative sequence in $(\mathrm{W}), \mathrm{P}_{\mathrm{ag} 2}$ is airgap power of negative sequence in (W) and $\mathrm{P}_{\text {mec } 2}$ is the mechanical power expended corresponding to negative sequence in (W)

If Equation (4) is applied to the steady state condition with slip values between 0.01 and 0.05 , the approximate equation shown in (8) is obtained. In this equation it is observed that the voltage unbalance has an effect on the reduction of the motor shaft power. It is also noted that this reduction effect is independent of the motor slip, so it will be more noticeable if the motor operates at less than the rated power.

$$
\mathrm{P}_{\text {out }}=3 \cdot \mathrm{r}_{21} \cdot\left(\frac{1-\mathrm{s}}{\mathrm{s}}\right) \cdot \mathrm{I}_{21}^{2}-\frac{3}{2} \cdot \mathrm{r}_{22} \cdot \mathrm{I}_{22}^{2}-\mathrm{P}_{\mathrm{fw}}
$$

Total losses and efficiency in the motor are:

$$
\begin{aligned}
& P_{\text {tot-loss }}=3 \cdot\left(r_{\mathrm{e}} \mathrm{I}_{1}^{2}+\mathrm{r}_{\mathrm{m}} \mathrm{I}_{\mathrm{ml}}^{2}+\mathrm{r}_{21} \cdot \mathrm{I}_{21}^{2}+\mathrm{r}_{\mathrm{e}} \mathrm{I}_{2}^{2}+\mathrm{r}_{\mathrm{m}} \cdot \mathrm{I}_{\mathrm{m} 2}^{2}+\mathrm{r}_{22} \cdot \mathrm{I}_{22}^{2}\right)+\mathrm{P}_{\mathrm{fw}} \\
& \eta=\frac{\mathrm{P}_{\text {out }}}{\mathrm{P}_{1}+\mathrm{P}_{2}} \cdot 100=\frac{\mathrm{P}_{\text {out }}}{\mathrm{P}_{\text {out }}+\mathrm{P}_{\text {tot-loss }}} \cdot 100
\end{aligned}
$$

where $\mathrm{P}_{\text {tot-loss }}$ is total losses in $\mathrm{W}$ and $\eta$ is the efficiency in (\%).

In Figure 2, the power flow in the motor under voltage unbalance conditions is shown, including electrical power, losses and power output of positive and negative sequence. 


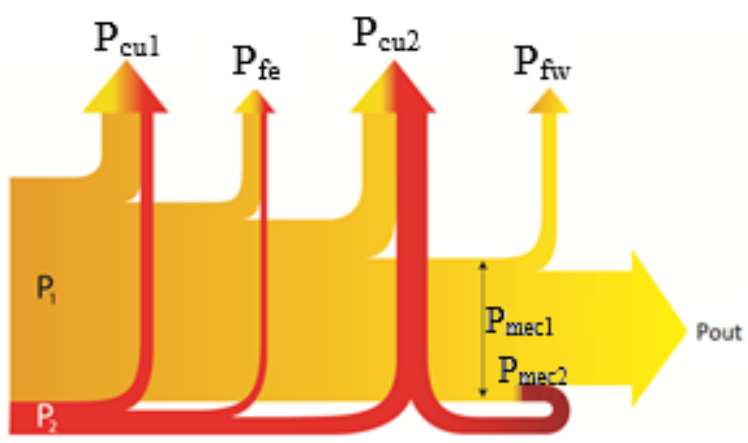

Figure 2. Induction motor power flow operating under unbalanced conditions considering the positive and negative sequence power

In Figure 2, $\mathrm{P}_{\mathrm{cu} 1}$ is the copper loss of positive sequence in $(\mathrm{W}), \mathrm{P}_{\mathrm{fe}}$ is core losses in $(\mathrm{W}), \mathrm{P}_{\mathrm{mec}}$ is the mechanical power developed of positive sequence in $(\mathrm{W})$.

\subsection{Effects of unbalanced voltages on the line currents}

The following describes a group of parameters that characterize voltage and current unbalance [19]. These are the complex current unbalance factor (CCUF), the complex voltage unbalance factor (CVUF), the current unbalance factor (CUF) and the voltage unbalance factor (VUF).

$$
\begin{aligned}
& \text { CCUF }=\frac{I_{2}}{I_{1}} \\
& \text { CVUF }=\frac{V_{2 f}}{V_{1 f}} \\
& C U F=\left|\frac{I_{2}}{I_{1}}\right| \\
& V U F=\left|\frac{V_{2 f}}{V_{1 f}}\right|
\end{aligned}
$$

The use of the brackets indicates the use only of the magnitudes, whereas when they are not used, it indicates the use of the magnitudes and angle. From Ohm's laws, the following relationships between these parameters can be established.

$$
\begin{aligned}
& \operatorname{CCUF}=\frac{\mathrm{I}_{2}}{\mathrm{I}_{1}}=\left(\frac{\mathrm{V}_{2 \mathrm{f}}}{\mathrm{V}_{1 \mathrm{f}}}\right)\left(\frac{\mathrm{Z}_{1}}{\mathrm{Z}_{2}}\right)=\operatorname{CVUF}\left(\frac{\mathrm{Z}_{1}}{\mathrm{Z}_{2}}\right) \\
& \mathrm{CUF}=\left|\frac{\mathrm{I}_{2}}{\mathrm{I}_{1}}\right|=\left|\frac{\mathrm{V}_{2}}{\mathrm{~V}_{1}} \cdot \frac{\mathrm{Z}_{1}}{\mathrm{Z}_{2}}\right|=\mathrm{VUF} \cdot\left|\frac{\mathrm{Z}_{1}}{\mathrm{Z}_{2}}\right| \\
& \mathrm{CCUF}=\mathrm{CUF} \angle \theta_{\mathrm{I} 2}-\theta_{\mathrm{I} 1}
\end{aligned}
$$

where $Z_{1}$ and $Z_{2}$ are the positive and negative sequence impedances of the respective equivalent circuits of Figure 1 in $(\Omega), \theta_{\mathrm{I} 2}$ and $\theta_{\mathrm{I} 1}$ are the phase angle of the positive and negative sequence currents. 
The equations of $\mathrm{Z} 1$ and $\mathrm{Z} 2$ are described below:

$$
\begin{aligned}
& \mathrm{Z}_{1}=\left(\mathrm{r}_{\mathrm{e}}+\mathrm{j}_{\mathrm{x} 1}\right)+\frac{\left(\mathrm{r}_{\mathrm{m}}+\mathrm{j} \mathrm{x}_{\mathrm{m}}\right) \cdot\left(\mathrm{r}_{21}+\mathrm{r}_{21} \cdot \frac{(1-\mathrm{s})}{\mathrm{s}}+\mathrm{j} \mathrm{x}_{21}\right)}{\mathrm{r}_{\mathrm{m}}+\mathrm{j} \mathrm{x}_{\mathrm{m}}+\mathrm{r}_{21}+\mathrm{r}_{21} \cdot \frac{(1-\mathrm{s})}{\mathrm{s}}+\mathrm{j} \mathrm{x}_{21}} \\
& \mathrm{Z}_{2}=\left(\mathrm{r}_{\mathrm{e}}+\mathrm{j}_{\mathrm{x} 1}\right)+\frac{\left(\mathrm{r}_{\mathrm{m}}+\mathrm{j} \mathrm{x}_{\mathrm{m}}\right) \cdot\left(\mathrm{r}_{22}+\mathrm{r}_{22} \cdot\left(\frac{\mathrm{s}-1}{2-\mathrm{s}}\right)+j \mathrm{x}_{22}\right)}{\mathrm{r}_{\mathrm{m}}+\mathrm{j} \mathrm{x}_{\mathrm{m}}+\mathrm{r}_{22}+\mathrm{r}_{22} \cdot\left(\frac{\mathrm{s}-1}{2-\mathrm{s}}\right)+j \mathrm{x}_{22}}
\end{aligned}
$$

Equations (15) and (16) show that the current unbalance is always greater than the voltage unbalance, in a multiple of the ratio of motor impedances. This explains that small voltage unbalances can produce large current unbalances affecting the electrical system. From Equations (11) and (17), the relationship between the negative and positive sequence current is:

$$
\mathrm{I}_{2}=\mathrm{I}_{1} \cdot \mathrm{CUF} \angle \theta_{\mathrm{I} 2}-\theta_{\mathrm{I} 1}
$$

From current sequence components and Equation (20) it can be deduce the next equations for the line currents. These equations allow to analyze the relationship between the line currents and the current unbalance CUF.

$$
\begin{aligned}
& \mathrm{I}_{\mathrm{a}}=\mathrm{I}_{1}+\mathrm{I}_{2}=\mathrm{I}_{1}\left(1+\mathrm{CUF} \cdot \angle \theta_{\mathrm{I} 2}-\theta_{\mathrm{I} 1}\right) \\
& \mathrm{I}_{\mathrm{b}}=\mathrm{a}^{2} \cdot \mathrm{I}_{1}+\mathrm{a} \cdot \mathrm{I}_{2}=\mathrm{I}_{1}\left(1 \angle 240^{\circ}+1 \angle 120^{\circ} \cdot \mathrm{CUF} \angle \theta_{\mathrm{I} 2}-\theta_{\mathrm{I} 1}\right) \\
& \mathrm{I}_{\mathrm{c}}=\mathrm{a} \cdot \mathrm{I}_{1}+\mathrm{a}^{2} \cdot \mathrm{I}_{2}=\mathrm{I}_{1}\left(1 \angle 120^{\circ}+1 \angle 240^{\circ} \cdot \mathrm{CUF} \cdot \angle \theta_{\mathrm{I} 2}-\theta_{\mathrm{I} 1}\right)
\end{aligned}
$$

Where $I_{a}, I_{b}$ and $I_{c}$ are line currents in $(A), a=e^{j \frac{2 \pi}{3}}$ is the complex operator used in the method of the symmetric components.

Applying the law of cosines to Equations (21), (22) and (23) and considering (20), the magnitude of the line currents based on the angle between the positive and negative sequence currents are:

$$
\begin{aligned}
& \left|I_{\mathrm{a}}\right|=\left|\frac{\mathrm{V}_{1}}{\mathrm{Z}_{1}}\right| \cdot \sqrt{1+2 \cdot \mathrm{VUF} \cdot\left|\frac{\mathrm{Z}_{1}}{\mathrm{Z}_{2}}\right| \cdot \cos \left(\theta_{\mathrm{I} 2}-\theta_{\mathrm{I} 1}\right)+\mathrm{VUF}^{2} \cdot\left|\frac{\mathrm{Z}_{1}}{\mathrm{Z}_{2}}\right|^{2}} \\
& \left|\mathrm{I}_{\mathrm{b}}\right|=\left|\frac{\mathrm{V}_{1}}{\mathrm{Z}_{1}}\right| \cdot \sqrt{1+2 \cdot \mathrm{VUF} \cdot\left|\frac{\mathrm{Z}_{1}}{\mathrm{Z}_{2}}\right| \cos \left(\theta_{\mathrm{I} 2}-\theta_{\mathrm{I} 1}-120^{\circ}\right)+\mathrm{VUF}^{2} \cdot\left|\frac{\mathrm{Z}_{1}}{\mathrm{Z}_{2}}\right|^{2}} \\
& \left|\mathrm{I}_{\mathrm{c}}\right|=\left|\frac{\mathrm{V}_{1}}{\mathrm{Z}_{1}}\right| \cdot \sqrt{1+2 \cdot \mathrm{VUF} \cdot\left|\frac{\mathrm{Z}_{1}}{\mathrm{Z}_{2}}\right| \cos \left(\theta_{\mathrm{I} 2}-\theta_{\mathrm{I} 1}-240^{\circ}\right)+\mathrm{VUF}^{2} \cdot\left|\frac{\mathrm{Z}_{1}}{\mathrm{Z}_{2}}\right|^{2}}
\end{aligned}
$$

Equations (24) to (26), demostrate that the currents depend on the magnitude of the positive sequence voltage, the VUF, the phase angle and sequence impedances. These models are more accurate than others for the analysis of the effect of voltage unbalance, since it presents more parameters of analysis. Instead, other models only consider the magnitude of the negative sequence voltage.

The current in each phase will have a maximum value represented by Equation (27) for a given VUF, $\mathrm{V}_{1}$ and a speed operation fixed. Another condition for obtaining the maximum value is that the positive and negative sequence current are in phase, thus $\left(\theta_{\mathrm{I} 2}-\theta_{\mathrm{I} 1}\right)=0$. 


$$
I_{\text {amax }}=\left|I_{1}\right| \cdot(1+C U F)=\left|\frac{V_{1}}{Z_{1}}\right| \cdot\left(1+\text { VUF } \cdot\left|\frac{Z_{1}}{Z_{2}}\right|\right)
$$

\subsection{Effect of the motor load on the current unbalanced}

In this section, the influence of the motor load on the current unbalance is analyzed. For the analysis, Equation (16) is used. According to this equation for a given unbalance with $V_{1 f}$ and $V_{2 f}$ fixed, the values of $I_{1}$ and $I_{2}$ depend on the variation of the impedance with the load. In turn, the impedance depends on the slip. Given the above, then it discusses how loading affects the behavior of the slip, the impedance and current of positive and negative sequence of motor.

For impedance $Z_{1}$, since the starting motor $(s=1)$ until the no-load condition $(s \approx 0.001)$, it is noted that the term, $r_{21} / s$ vary from $r_{21}$ until 1000 times $r_{21}$. Therefore the value of $Z_{1}$ is strongly dependent of the slip and its value increased from the start to the point of no-load.

For the impedance $Z_{2}$, since the starting motor $(s=1)$ until the no-load condition $(s \approx 0,001)$. It is noted that the term, $r_{22} / s$ varies from $r_{22}$ until $r_{22} / 2$. Therefore, the value of $Z_{2}$ varies very little with the slip and his value decrease slightly from the start to the point of no-load.

\subsection{Effect on the motor losses}

In voltage unbalance conditions, the losses are increased because the component of the negative sequence voltage generates a magnetic field in the opposite direction to the rotation of the motor. The study of the effects of voltage unbalance on induction motor losses are important because it allows to quantify the reduction in efficiency, the over consumption of energy and the increase in operating costs [23]-[25].

The copper losses due to the positive sequence voltage dependent on the magnitude of $\mathrm{V}_{\text {lf }}$ and the motor load. While copper losses caused by negative sequence voltage are practically constant with the motor load and are mainly defined by the magnitude of the negative sequence voltage $\mathrm{V}_{2 \mathrm{f}}$. In general, the effect of voltage unbalance in copper losses is more noticeable when the motor is under load.

The iron loss can be expressed according to the voltage unbalance as:

$$
P_{\text {fe }}=3 \cdot r_{m} \cdot\left(\left|\frac{V_{1 f}}{Z_{m}}\right|^{2}+\left|\frac{V_{2 f}}{Z_{m}}\right|^{2}\right)=3 \cdot r_{m} \cdot\left|\frac{V_{1 f}}{Z_{m}}\right|^{2}\left(1+V_{U F}^{2}\right)
$$

where $Z_{m}$ is the impedance of the magnetization branch in $(\Omega)$, composed of $r_{m}$ and $x_{m}$.

The Equation (28) shows that the iron losses depend on the square of the magnitude of the positive sequence voltage component and the square of VUF. The VUF squared is much smaller than unity, therefore these losses are mainly caused by the positive sequence component of voltage. It's important pointing that if the positive sequence voltage is greater than the nominal voltage, for a given VUF increase the iron losses in the motor. Therefore, if the motor is made of a magnetic flux of density close to the saturation zone, the increase in these losses can be significant and cause excessive heating.

The friction and windage losses are little influenced by unbalanced voltage.

\subsection{Effect on the efficiency and the power factor}

The efficiency and power factor are important components that determine the energy performance of the induction motor.The apparent power absorbed by the motor in voltage unbalance condition is:

$$
S_{\text {elec }}=3 \cdot V_{1 \mathrm{f}} \cdot I_{1}^{*}+3 \cdot V_{2 f} \cdot I_{2}^{*}=3 \cdot \frac{\left|V_{1 f}\right|^{2}}{Z_{1}^{*}}+3 \cdot \frac{\left|V_{2 f}\right|^{2}}{Z_{2}^{*}}
$$

where $\mathrm{S}_{\text {elec }}$ is the apparent power absorbed by the motor in (VA), and the asterix $\left(^{*}\right)$ indicates the conjugate of the parameters where it is used.

$$
\begin{aligned}
& \mathrm{P}_{\text {elec }}=\mathrm{R}_{\text {eal }}\left[\mathrm{S}_{\text {elec }}\right] \\
& \mathrm{Q}_{\text {elec }}=\mathrm{I}_{\text {mag }}\left[\mathrm{S}_{\text {elec }}\right]
\end{aligned}
$$

where $Q_{\text {elec }}$ is the reactive power consumed in (VAr), $R_{\text {eal }}$ is the real component and $I_{\text {mag }}$ is the imaginary component. 
In (29) it is shown that the apparent power input $S_{\text {ent }}$ in unbalanced conditions, has two components that depends on the magnitude of the voltage and impedances sequence. The positive sequence component changes with the motor load while the negative sequence component remains practically constant, since the negative sequence of impedance not change with the load. The efficiency and power factor can be expressed as:

$$
\begin{gathered}
\eta=\frac{P_{\text {out }}}{R_{e_{\text {al }}}\left[S_{\text {ent }}\right]} \\
F p=\frac{R_{e_{\text {al }}}\left[S_{\text {ent }}\right]}{\left|S_{\text {ent }}\right|}
\end{gathered}
$$

In (29), (30), (31), (32) and (33) is showed that the efficiency and power factor dependent of VUF, $\mathrm{V}_{1}$ and the motor load. This result shows that in the analysis of the efficiency and power factor, the positive sequence voltage must be considered, not only the negative sequence as it is done in some models of analysis of the effects of voltage unbalance.

\section{RESULTS AND ANALYSIS.}

In this section, the described models for the analysis of the effects of voltage unbalance are applied to a case study in an induction motor. The models was implemented in the Scilab Software.

The motor data are: Induction three-phase motor, Standard NEMA, 3 HP, 220V, 8.4 A, 60 Hz, 1740 RPM, Frame 225, Design B.

The parameters of the equivalent circuit of the motor, obtained from no-load and locked rotor tests for unbalanced voltage, following the procedures of [4] and [9] are: $\mathrm{r}_{\mathrm{e}}=0.78 \Omega, \mathrm{r}_{\mathrm{m}}=1.573 \Omega, \mathrm{r}_{21}=0.599 \Omega$, $\mathrm{r}_{22}=1.054 \Omega, \mathrm{x}_{1}=0.951 \Omega, \mathrm{x}_{\mathrm{m}}=26.447 \Omega, \mathrm{x}_{21}=1.509 \Omega, \mathrm{x}_{22}=1.473 \Omega, \mathrm{P}_{\mathrm{fw}}=9.76 \mathrm{~W}$.

First, the behavior of the impedance with the variation of the load and the slip from the blocked rotor condition to the nominal operating conditions (from $s=1$ to $s=0.001$ ) was analyzed. The models of Equations (18) and (19) were used. Figure 3 shows the results of the behavior of the impedance in these conditions.

In this figure is observed since the highest value of (s) in no-load condition to its lowest value in blocked rotor condition, that the positive sequence impedance $Z_{1}$ strongly dependent on the slip. The most variation of $Z_{1}$ occurs at low slip, specifically in the zone of steady state operation. The figure also shows that the negative sequence impedance $Z_{2}$, practically no depend of the slip so for practical purposes, can be regarded as constant. It also shows that the value of $\mathrm{Z}_{2}$, is slightly higher in the starter.

Another interesting fact shown is that the negative sequence impedance at nominal slip $Z_{2 n o m}$, has a value very close to the impedance of the positive sequence at the point of locked rotor $\mathrm{Z}_{1 \mathrm{rb}}$. This phenomenon is explained by the effect of the displacement of the negative sequence current, which causes that the negative sequence resistance of the rotor to be greater than the positive sequence resistance [18], [20]-[22].

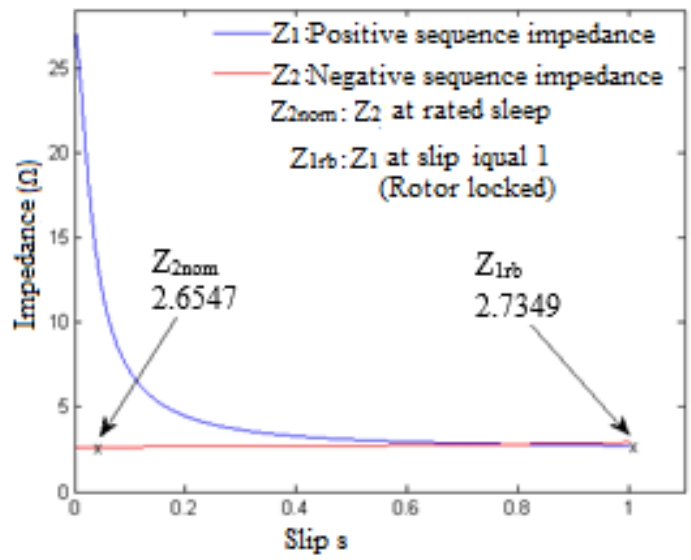

Figure 3. Variation of the sequence impedances with the slip 
The Equation (16) establishes that the CUF is equal to the VUF multiplied by the ratio of impedances. As seen above, in the motor operation zone $\mathrm{Z}_{2}$ is kept constant while $\mathrm{Z}_{1}$ increases when the load is reduced. Consequently the result will be that the CUF increases sharply with decreasing of motor load. The Figure 4 shows this behavior in the variation of CUF (\%) with motor slip. As it is observed, in this case an unbalance of current increased in 10 times the unbalanced voltage.

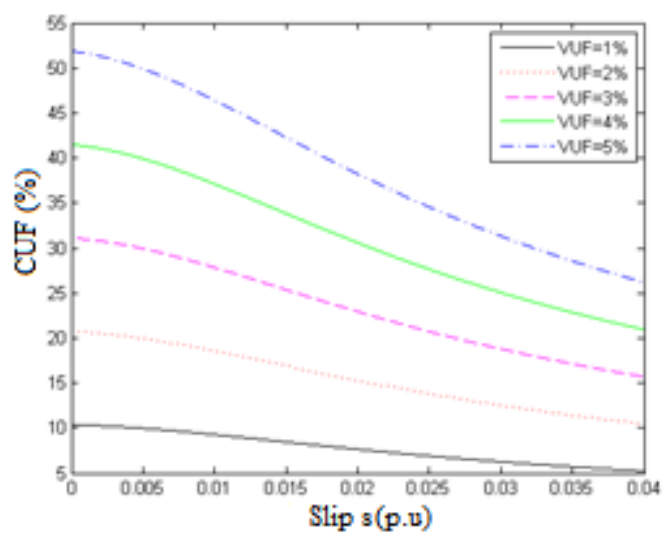

Figure 4. Variation of the CUF\% for $3 \mathrm{HP}$ motor $220 \mathrm{~V}, 60 \mathrm{~Hz}$

Table 1, shows how the relationship $\left(Z_{1} / Z_{2}\right)$ varies for the three typical motor speeds: no-load, rated and locked rotor. It is evident that in no-load the value of the current unbalance is 7-11 times the voltage unbalance.

Table 1. Ratio of the Values of the Sequence Impedance for Several Operation Point of the Motor

\begin{tabular}{cccc}
\hline Operation Point & No load & Rated load & Locked rotor \\
\hline$\left|Z_{1} / Z_{2}\right|$ & 10.4 & 5.66 & 0.99 \\
\hline
\end{tabular}

Figure 5 shows the behavior of the efficiency (Figure 5(a)) and the power factor (Figure 5(b)) for three values of V1 $(0.95 \mathrm{Vn}, \mathrm{Vn}$ and $1.05 \mathrm{Vn})$, different values of VUF and a fixed angle of CVUF. In this way, the behavior of these parameters can be analyzed, not only for the unbalance but also for the voltage variation.

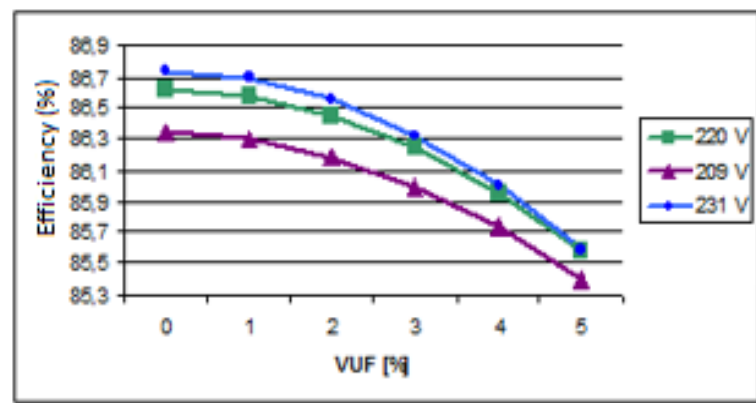

(a)

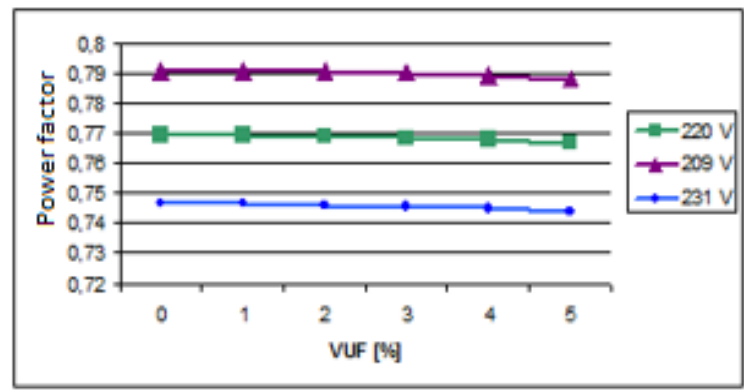

(b)

Figure 5. (a)Variation of the efficiency (a) and power factor (b) with diferents values of $\mathrm{V}_{1}$, VUF, keeping constant the value of CVUF

Figure 5 (a) shows that the efficiency of the motor under study presents the worst performance for the highest voltage unbalance and the lowest voltage. This is because the increase in voltage unbalance increases the effects of this phenomenon on motor losses. In relation to the variation of voltage, when the

Unbalanced Voltages Impacts on the Energy Performance of Induction Motors (Enrique C. Quispe) 
motor operates at nominal load, the decrease in voltage produce an increase in current to meet the demand and therefore copper losses increase.

Figure 5(b) shows that the power factor decreases with increasing unbalance, but to a lesser degree than efficiency. On the other hand, higher power factor is obtained at a lower operating voltage. This is because the power factor depends directly on the voltage magnitude.

\section{CONCLUSION}

The models proposed in this article constitute a valuable tool to analyze the effect of voltage unbalance in the operation of induction motors, specifically in current consumption, efficiency and power factor, considering also other operating parameters such as the slip and the variation of voltage. These models, unlike others previously proposed that only consider the negative sequence voltage, also analyze the influence of the negative sequence voltage, positive sequence voltage and the angle between them.

The models show that the voltage unbalance significantly increases the current unbalance in a multiple that depends on the impedance of the motor. In the case of the study analyzed, this increase was 10 times, which justifies the need to mitigate the phenomenon once it is detected. This current unbalance produces the elliptical flow that reduces the operation efficiency of the motor and produces negative effects in the electrical networks as maladjustment in the protections, over heating, among others.

The results of the study show that under voltage unbalance conditions, the unbalance currents depends on: the VUF; the angle of the CVUF; the positive sequence impedance and the motor speed.

The analysis of the effect of the voltage unbalance in the operation of the motor showed that the copper losses, which are the main losses of the motor, caused by the positive sequence voltage, behaves differently to the copper losses of negative sequence. The first losses depend on the positive sequence voltage and the load, while the second one depends only on the negative sequence voltage.

The results also showed that the positive sequence impedance is very sensitive in relation to the variability of the load, however, the negative sequence impedance practically does not vary with the load. This same result applies to all positive and negative sequence operating parameters that depend on the impedance such as power consumption, losses and power factor, among others.

The case study showed the negative effects produced by the voltage unbalance and the voltage variation in the efficiency and the power factor of the motor. In the case of efficiency, the effect was more significant.

\section{REFERENCES}

[1] M. Sulaiman, Z. Salleh, and R. Omar, "Effects of parameters variation in fuzzy based induction motor drives", Indonesian Journal of Electrical Engineering and Computer Science, vol. 16, No. 2, pp. 272-280, Nov. 2015.

[2] V. Sousa, P. R. Viego, J. R. Gómez, E. C. Quispe and M. Balbis, "Estimating induction motor efficiency under nocontrolled conditions in the presences of unbalanced and harmonics voltages," in Proceedings CHILEAN Conference on Electrical, Electronics Engineering, Information and Communication Technologies (CHILECON), 2015, pp. 567-572.

[3] V. S. Santos, P. V Felipe and J. G. Sarduy, "Bacterial foraging algorithm application for induction motor field efficiency estimation under unbalanced voltages" Measurement, vol. 46, no.7, pp. 2232-2237, Aug. 2013.

[4] S. M. Ahmed, H. Abu-Rub, S. S. Refaat and A. Iqbal, "Diagnosis of stator turn-to-turn fault and stator voltage unbalance fault using ANFIS," International Journal of Electrical and Computer Engineering, vol. 3, No. 1, pp. 129-135, Feb. 2015.

[5] M. Al-Badri, P. Pillay and P. Angers, "A novel in situ efficiency estimation algorithm for three-phase induction motors operating with distorted unbalanced voltages," IEEE Transactions on Industry Applications, vol. 53, no. 6, pp. 5338-5347, 2017.

[6] G. J. Retter, "Matrix and Space-Phasor Theory of Electrical Machines", Académiai Kiadó, 1987, p. 411.

[7] A. Siddique, G.S. Yadava and B. Singh, "Effect of voltage unbalance on induction motors", in Proceedings IEEE International Symposium on Electrical Insulation, 2004, pp. 26-29.

[8] J. R. Linders, "Effect of power supply variations on ac motor characteristics," IEEE Transactions on Industry Applications, vol. IA-8, no. 4, pp. 383-400, July/August 1972.

[9] "IEC Rotating Electrical Machines - Part 26: Effects on unbalanced voltages on the performance of induction motors", IEC Standard 60034-26, Geneva, Switzerland, 2006.

[10] M.A. de Armas, J. Gomez, "Análisis generalizado de los motores asíncronos con alimentación desbalanceada o no mediante la teoría de los campos rotatorios," Energética, no. 39, pp. 5-11, 2008.

[11] Y. J. Wang, "Analysis of effects of three-phase voltage unbalance on induction motors with emphasis on the angle of the complex voltage unbalance factor," IEEE Transactions on Energy Conversion, vol. 16, no. 3, pp. 270-275, Sept. 2001

[12] J. Faiz, H. Ebrahimpour, and P. Pillay, "Influence of unbalanced voltage on the steady-state performance of a threephase squirrel-cage induction motor," IEEE Transactions on Energy Conversion, vol. 19, no. 4, pp. 657-662, 2004. 
[13] A. Costa, and X. M. Lopez Fernandez, "Effects of unbalanced power supply on efficient performance of three phase induction motors", in Proceedings XL International Symposium on Electrical Machines SME'2004, 2004, pp. 15-18.

[14] "NEMA Motors and Generators", Standard Publication ANSI/NEMA MG1-2003, Revision 1-2004, Publishing by NEMA, Rosslyn, USA, 2003.

[15] A. M. S. Mendes, E. C. Quispe, X. M. López-Fernández, and A. J. Marques Cardoso, "Influence of the positive sequence voltage on the temperature of three-phase induction motors," in Proceedings XIX International Conference on Electrical Machines - ICEM 2010, 2010, pp. 1-6.

[16] E. C. Quispe, X. M. López-Fernández, A. M. S. Mendes, A. J. Marques Cardoso and J. A. Palacios, "Experimental Study of the effect of positive sequence voltage on the derating of three-phase induction motors under voltage unbalance", in Proceedings 2011 IEEE International Electric Machines \& Drives Conference (IEMDC), 2011, pp. 908-912.

[17] M. Jannati, T. Sutikno, N. R. N. Idris and M. J. A. Aziz, "Modeling of balanced and unbalanced three-phase induction motor under balanced and unbalanced supply based on winding function method," International Journal of Electrical and Computer Engineering, vol. 5, No. 4, pp. 644-655, Aug. 2015.

[18] E. C. Quispe, "Efectos del desequilibrio de tensiones sobre la operación del motor de inducción trifásico. Énfasis en la caracterización del desequilibrio de tensiones y el efecto sobre la potencia nominal," Ph.D. Dissertation, School of Electrical and Electronic Engineering, Univ. Del Valle, Colombia, 2012.

[19] S.E.M. de Oliveira, "Operation of three-phase induction connected to one-phase supply," IEEE Transaction on Energy Conversion, vol. 5, no. 4, pp. 713-718, Dec. 1990.

[20] P.C. Cochran, "Polyphase induction motors: analysis, desing and application", Copyright 1989 by Marcel Dekker, Inc., Print in USA, New York, 1989. p. 678.

[21] M. Kostic, and A. Nicolic, "Negative consequence of motor voltage asymmetry and its influence to the unefficient energy usage," WSEAS Transactions on Circuits and Systems, vol. 9, no. 8, pp. 547-552, Aug. 2010.

[22] E. C. Quispe, X. M. Lopez-Fernandez, A. M. S. Mendes, A. J. Marquez-Cardoso and J. A. Palacios. "Influence of the positive sequence voltage on the derating of three-phase induction motors under voltage unbalance", in Proceedings 2013 IEEE International Electric Machines \& Drives Conference (IEMDC), 2013, pp. 100-105.

[23] E. C. Quispe, "Una visión integral para el uso racional de la energía en la aplicación de los motores eléctricos de inducción,” Revista El Hombre y la Maquina, No. 20-21, pp. 52-59, Jul/Dic 2003.

[24] A. Eltom, and M.A. Aziz, "The economics of energy efficient motors during unbalanced voltage condition", in Proceedings of the Inaugural IEEE Power Engineering Society PES Conference and Exposition in Africa, 2005, pp. 378-384.

[25] J. Faiz, H. Ebrahimpour, and P. Pillay, "Influence of unbalanced voltage supply of three phase squirrel cage induction motor and economic analysis," Energy Conversion and Management, vol. 47, no. 3, pp. 289-302, Feb, 2006.

\section{BIOGRAPHIES OF AUTHORS}

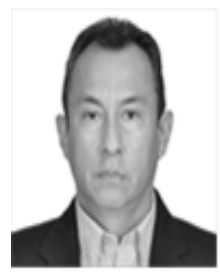

Enrique C. Quispe (M'95. SM'12) was born in Lima, Perú, on January 20, 1956. He received the B.Sc. in Electrical Engineering from the Universidad Nacional de Ingeniería, Perú in 1980. M.Sc. in Electrical Engineering, M. Eng. in Industrial Automation and PhD. in Electrical Engineering from Universidad del Valle, Colombia in 1994, 1997 and 2011, respectively. Since 1992, he has been with Universidad Autónoma de Occidente, Cali, Colombia, where he is currently Full Professor in the Department of Energy and Mechanics and the Director of the Energy Research Group. His current research interests include the analysis of electrical machines and drives, power quality and management and energy efficiency. He is an IEEE Senior Member.

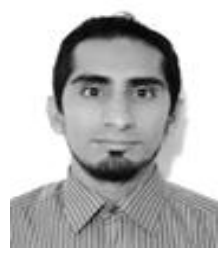

Iván D. López was born in Mocoa, Putumayo, on June 10, 1986. He received the B. Sc. In Electrical Engineering from the Universidad del Valle, Colombia in 2010. He is currently studying the master's degree in electrical engineering at Universidad del Valle, Colombia.Since 2014 he is Deputy Manager at Tenorio García y Cía. Ltda. Since 2014 he has served as part time adjunct professor in the Electrical Engineering Program at Universidad Autónoma de Occidente. His area of interest includes the analysis of electrical machines, power quality and energy efficiency.

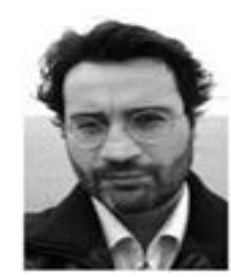

Fernando J. T. E. Ferreira (SM'09) received the Ph.D. in electrical engineering in 2009, from the University of Coimbra, Coimbra, Portugal. He is currently a Professor in the Department of Electrical and Computer Engineering, University of Coimbra. Since 1998, he has been a Researcher in the Institute of Systems and Robotics, University of Coimbra (ISR-UC), and has participated in several European projects dealing with electric motor technologies. He is the coauthor of more than 100 papers published in international journals and conference records. Dr. Ferreira was a recipient of the Best Paper Award at the 2001 IEEE/IAS Industrial and Commercial Power Systems Technical Conference, and of the Best Poster Presentation Award at the 2010 International Conference on Electrical Machines. 
Vladimir Sousa Santos was born in Cienfuegos, Cuba on November 21, 1980. Received the B.S degree in Electrical Engineering from Universidad Central de Las Villas, Santa Clara. Cuba, in 2004. Received the M.Sc. degree in Energy Efficiency from the Universidad de Cienfuegos, Cuba in 2006. Received the Dr.C. (Ph.D.) degree from the Universidad Central de Las Villas, Santa Clara, Cuba, in 2014. Currently is with Energy Department of the Faculty of Engineering of Universidad de la Costa (CUC). Barranquilla. Colombia. His area of interest includes electric machines, power quality and energy efficiency. 